\title{
Routine prenatal ultrasonography: The pregnant woman's expectations and perspectives on safety in a Central African obstetric population
}

\author{
Joshua Tambe $^{1 *}$, Boniface Moifo ${ }^{1}$, Odile Fernande Zeh ${ }^{1}$, Pascal Foumane ${ }^{2,3}$, Joseph Gonsu Fotsin ${ }^{1}$, \\ Robinson Enow Mbu $^{3}$ \\ ${ }^{1}$ Radiology Department, Gyneco-Obstetric and Pediatric Hospital, Yaounde, Cameroon \\ ${ }^{2}$ Obstetrics and Gynecology Department, Gyneco-Obstetric and Pediatric Hospital, Yaounde, Cameroon \\ ${ }^{3}$ Obstetrics and Gynecology Department, Faculty of Medicine and Biomedical Sciences, The University of Yaounde 1, Yaounde, \\ Cameroon \\ Email: ${ }^{\text {tambej@yahoo.fr }}$
}

Received 6 August 2013; revised 27 August 2013; accepted 3 September 2013

Copyright (C) 2013 Joshua Tambe et al. This is an open access article distributed under the Creative Commons Attribution License, which permits unrestricted use, distribution, and reproduction in any medium, provided the original work is properly cited.

\begin{abstract}
Background: Pregnant women are important stakeholders regarding prenatal ultrasound (US) scanning. Their specific needs and preferences have to be ascertained by healthcare providers to ameliorate service delivery. Objective: To assess the pregnant woman's expectations during routine prenatal US scan and her perspective of US safety during pregnancy in a Central African obstetric population. Methods: A cross-sectional descriptive survey of consenting pregnant women who reported for routine prenatal US scan using an anonymous questionnaire. A convenient sample of 200 participants was adopted. Results: Thirty-three $(16.8 \%)$ respondents (on a total of 196) declared they had never done an US scan. One hundred and eleven $(58.4 \%)$ on a total of 190 stated that they had not received any information on what ultrasonography is all about. Before the US scan the respondents would like to receive information on the aim or purpose of ultrasonography, possible inconveniences or risks, and on how to prepare before the scan. The most reported expectations were assurance of the wellbeing of the fetus $(58 \%)$, gender determination (44.5\%) and information on fetal position (20.5\%). Thirty-four respondents considered ultrasonography as not perfectly safe for the mother or the "baby", with the relevant reasons being the use or production of some potentially harmful "rays". Conclusion: Pregnant women would want to be assured of the wellbeing of the fetus, the gender and position during routine prenatal US. They however need to be informed of its purpose and safety.
\end{abstract}

"Corresponding author.
Keywords: Routine Prenatal US; Expectations; US Safety

\section{INTRODUCTION}

Routine prenatal ultrasound (US) screening is an integral part of the follow-up of pregnancy in many countries. However, expert views on its use remain controversial with the main aspects of contention being benefits, cost and ethical considerations [1]. Over the years US scans have become more and more available in developing countries with increasing accessibility, enhancing its routine use in the follow-up of pregnancies by healthcare providers [2].

The pregnant woman is an important stakeholder regarding prenatal ultrasonography. Her acceptance of the procedure and willingness to pay for it as is often the case in some developing countries where health insurance policies are quasi-inexistent for the majority of the population are factors that can contribute to its success as a tool in pregnancy assessment. Achieving this will very likely depend on her knowledge and understanding of the potential benefits and limitations of this utility over inconveniences and risks, if any [3]. In some studies, participants declared having received background information on the purposes of US scan [1,4], while in others this was not the case $[3,5]$. This trend of awareness of information regarding prenatal US warrants further investigations across different populations so as to confront local realities.

Some published materials on the expectations of pregnant women who report for prenatal US scans have been similar across some different populations with significant variations in the reasons behind the expectations based 
on socio-economic and cultural differences [3,5,6]. Also, although US appears safe for clinical practice, as no study has yet proven the contrary, it is worthwhile investigating what the pregnant women think about its safety. This will help dispel some "myths" and erroneous perceptions regarding US during pre-scan preparation.

Cameroon is a major economical support in the Central African region and is often described as "Africa in miniature" due to its immense cultural diversity with two official languages, English and French. So far, no documented information is available on the pregnant woman's expectations and background knowledge of prenatal ultrasonography in this setting. Would these expectations be similar as earlier reported in other populations? Do these women have enough background information regarding the purpose of the scans? Furthermore what do these pregnant women know about US safety in pregnancy? It is with these questions in mind that this study was carried out with main objective to assess the pregnant woman's expectations during routine prenatal ultrasonography and her perspective of US safety during pregnancy.

\section{MATERIALS AND METHODS}

The study was carried out at a tertiary university-affiliated hospital in Yaounde specialized in maternal and child healthcare from July to November 2012. Authorization was obtained from the local hospital authorities. It was a cross-sectional survey during which pregnant women who reported to the Radiology department for routine prenatal ultrasonography constituted the study population. The study was explained to the pregnant women and those who were consenting were recruited. Informed consent was either verbal or written through the signing of an informed consent form. A convenient sample of 200 respondents was adopted for the study.

Data collection was achieved by means of an anonymous pre-tested self-administered questionnaire, drafted in English and in French due to the bilingual nature of the locality. However for some pregnant women who could not read and/or write English or French assistance was obtained from a nurse attendant at the Radiology department who explained the questions and noted down the responses. One nurse performed this function throughout the study in order to achieve consistency in explanations and interpretation of responses. The questionnaires were administered before the ultrasound scan and contained both open-ended and closed-ended questions. The main items included age, marital status, number of pregnancies, number of previous US scans, trimester of pregnancy, information received before US scan, desired information before US scan, expectations, and knowledge on US safety.

Data were entered into the statistical software SPSS 20.0 (IBM SPSS Inc., Chicago, USA) and subsequently analyzed. Means of continuous variables were compared using analysis of variance, and the threshold for statistical significance was set at 0.05 where applicable. For the open questions, responses judged similar in meaning were grouped together.

\section{RESULTS}

\subsection{Demographics and Background Information}

One hundred and twenty-two (61\%) respondents declared they were married. The 25 - 29 years age group was the most represented (31\%). Figure 1 shows the age-group distribution of the respondents.

The mean age of the respondents was $27.9 \pm 6.1$ years (mean \pm standard deviation), with age range from 15 to 44 years. The mean age was found to significantly differ between the married ( $30.1 \pm 6.0$ years) and the unmarried (26.4 \pm 5.7 years) pregnant women $(p<0.01)$. Figure 2 illustrates the age distribution with respect to marital status.

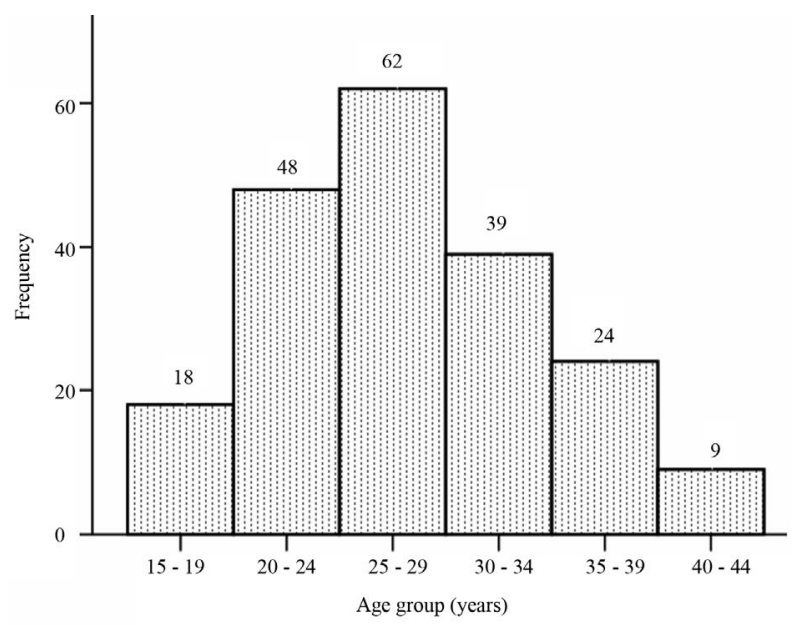

Figure 1. Age group distribution of respondents.

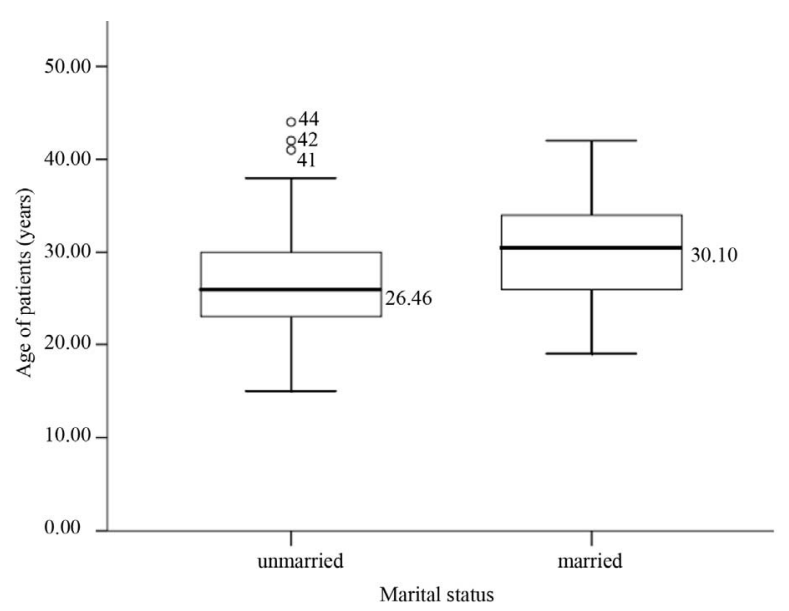

Figure 2. Age distribution of respondents with respect to marital status. 
The number of previous pregnancies ranged from 0 to 9. Forty-eight respondents (out of 200 ), that is $24 \%$, were at their first pregnancy. Thirty-six respondents (out of 192) accounting for $18.7 \%$ declared never to have undergone any previous US scan.

Concerning the prescription of US, 168 scans (89.8\%) were requested by obstetricians and gynecologists and resident doctors in Obstetrics and Gynecology. This was followed by $5.9 \%$ for general practitioners, $2.7 \%$ for self-referrals and $1.6 \%$ for nurses/midwives. Data on this item was available for 187 participants.

Seventy-eight (39.8\%) participants were in the second trimester of pregnancy, while 51 (26\%) and 67 (34.2\%) were in the first and third trimesters respectively (for a total of 196 available responses). One hundred and eleven (58.4\%) participants stated that they had received no information from their healthcare provider on what US is all about before the scan (data available for 190 participants). The information that the respondents admitted they would like to have before doing an US scan is presented in Table 1.

\subsection{Expectations and Ultrasound Safety}

The expectations of the pregnant women were assessed and related responses grouped together. Table 2 shows the expectations with respect to the trimester of pregnancy.

Ninety-three (46.5\%) respondents considered US to be perfectly safe for them and the unborn baby, 73 (36.5\%) selected the "I don't know" proposition while 34 (17\%) considered ultrasonography as not perfectly safe for the mother or the baby. Of the 34 respondents who thought US might not be perfectly safe, the relevant reasons advanced included the following: there is the use of "rays" which may have a "negative" or "destructive" effect on the baby; the ultrasound machine produces " $\mathrm{X}$ rays" which might have some "unnoticeable" effects that are

Table 1. Desired information before ultrasonography.

\begin{tabular}{cc}
\hline Items & Frequency (\%) \\
\hline $\begin{array}{c}\text { Aim/goal/reason/role/purpose/advantages/what } \\
\text { US is all about }\end{array}$ & $17(32.7)$ \\
Possible risks/dangers/inconveniences of US & $16(30.8)$ \\
Preparation before the procedure & $7(13.5)$ \\
$\begin{array}{c}\text { Explanation of the procedure } \\
\text { Assurance of communication of } \\
\text { findings during the US scan }\end{array}$ & $4(7.7)$ \\
Information on reliability of US scan findings & $2(3.8)$ \\
Irrelevant $^{\text {Total }}$ & $2(3.8)$ \\
\end{tabular}

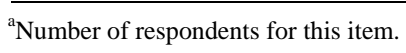

Table 2. Expectations with respect to trimester of pregnancy.

\begin{tabular}{ccccc}
\hline Item & $\begin{array}{c}\text { First } \\
\text { trimester }\end{array}$ & $\begin{array}{c}\text { Second } \\
\text { trimester }\end{array}$ & $\begin{array}{c}\text { Third } \\
\text { trimester }\end{array}$ & $\begin{array}{c}\text { Frequency } \\
(\%)^{\mathrm{b}}\end{array}$ \\
\hline Assurance of wellbeing & 34 & 52 & 30 & $116(58)$ \\
Gender & 8 & 49 & 32 & $89(44.5)$ \\
Position of the "baby" & 7 & 13 & 21 & $41(20.5)$ \\
Morphology of "baby" & 5 & 11 & 8 & $24(12)$ \\
Weight & 0 & 2 & 9 & $11(5.5)$ \\
Pregnancy evolution & 5 & 5 & 0 & $10(5)$ \\
Confirm pregnancy & 9 & 1 & 0 & $10(5)$ \\
Number of "babies” & 4 & 5 & 0 & $9(4.5)$ \\
Gestational age & 4 & 3 & 1 & $8(4)$ \\
EDC & 0 & 2 & 5 & $7(3.5)$ \\
Presentation & 0 & 0 & 2 & $2(1)$ \\
Placenta position & 0 & 0 & 2 & $2(1)$ \\
\hline
\end{tabular}

${ }^{a}$ EDC: Expected date of confinement. ${ }^{b}$ Percentages were calculated from the total number of respondents (200).

potentially harmful. Responses judged to be irrelevant included statements such as "It is God who is protecting us", "One can never know", "We just do with what we have", "What else can we do?"

\section{DISCUSSION}

The fact that more than half of the respondents declared having received no information from their healthcare providers on what US is all about seems surprising and unexpected given that most of the healthcare providers who referred these women were obstetricians and gynecologists or residents. If these declarations hold true then a probe into the possible reasons for this situation would be necessary. Could a high workload be responsible for this situation such that the healthcare providers do not have enough time to spend with their patients/clients? Given that US is now relatively widely available, do these healthcare providers assume that these women should already know sufficiently about the purpose of US, as many would have had one done before? From these results we can reservedly say that there is still to be done when it comes to keeping the pregnant woman informed on the role of US during pregnancy, as some authors reported [3,5]. A comprehensive explanation would likely contribute to the pregnant woman's acceptance and active participation, and will also remove any possible doubt on the integrity of the clinician, not neglecting the fact that financial gain could have motivated the request for the US scan.

The expectations of the pregnant women were generally relevant with respect to the term of the pregnancy, 
with the most frequent being general assurance of the wellbeing of the fetus, the gender and the position [3,511]. However, some expectations were irrelevant with respect to the trimester of pregnancy, such as the quest for gender in the first trimester. It is worth noting that some pregnant women begin antenatal consultations at any stage of the pregnancy, at times at their discretion and convenience, and so an US scan can present at any stage of an ongoing pregnancy.

Most of the pregnant women considered prenatal ultrasonography as safe, while others think some potentially harmful invisible "rays" are involved in the process. A similar finding had been earlier reported in a study carried out in Tanzania [5]. It would be necessary to educate pregnant women on the safety of US during pregnancy, so they won't have to live with the fear of a potential harm to the unborn baby or attribute adverse pregnancy outcomes to US. However this should not open the door to abuse and irrational use. The use of US as a diagnostic or screening tool in pregnancy should always be cautioned by healthcare providers [2]. Healthcare providers therefore have a big role in improving on the quality of care they provide to the service users. They can make use of guidelines to ensure that the services they provide are of the highest possible standard and meet the need of the individual users, so as to ameliorate the quality of healthcare through improved service delivery [12].

The limitations of this survey could be associated with the sampling method as participants were not randomly selected. Also we did not have a $100 \%$ response rate for all of the items on the questionnaire. However for those questions which directly responded to the objectives of the study we had a $100 \%$ response rate in two and $95 \%$ in one. Also, a source of bias inherent to the study design is reporting bias.

\section{ACKNOWLEDGEMENTS}

The authors wish to thank Mrs. Solange Sokoudjou for administering the questionnaires and Mrs. Arabella Tambe for proofreading the manuscript.

\section{REFERENCES}

[1] Larsen, T., Nguyen, T.H., Munk, M., Svendsen, L. and Teisner, L. (2000) Ultrasound screening in the 2nd trimester. The pregnant woman's background knowledge, expectations, experiences and acceptances. Ultrasound in
Obstetrics and Gynecology, 15, 383-386. doi:10.1046/j.1469-0705.2000.00112.x

[2] Kongnyuy, E.J. and van den Broek, N. (2007) The use of ultrasonography in obstetrics in developing countries. Tropical Doctor, 37, 70-72. doi:10.1258/004947507780609310

[3] Ugwu, A.C., Osungbade, E.O. and Erondu, F.O. (2009) Maternal perspectives of prenatal sonogram in a northeastern population in Nigeria. Libyan Journal of Medicine, 4, 140-142. doi:10.4176/090424

[4] Ugwu, A.C., Udo, B.E., Eze, J.C. and Erondu, O.F. (2011) Awareness of information, expectations and experiences among women for obstetric sonography in a south east Nigeria population. American Journal of Scientific and Industrial Research, 2, 478-481. doi:10.5251/ajsir.2011.2.4.478.481

[5] Firth, E.R., Mlay, P., Walker, R. and Sill, P.R. (2011) Pregnant women's beliefs, expectations and experiences of antenatal ultrasound in Northern Tanzania. African Journal of Reproductive Health, 15, 91-107.

[6] Stephens, M., Montefalcon, R. and Lane, D. (2000) The maternal perspective on prenatal ultrasound. Journal of Family Practice, 49, 601-604.

http://www.jfponline.com/index.php?id=22143\&tx ttnew s[tt_news] $=168676$

[7] Ekele, B.A., Maaji, S.M., Bello, S.O. and MoharsonBello, I.O. (2008) Profile of women seeking fetal gender at ultrasound in a Nigerian obstetric population. Ultrasound, 16, 199-202. doi:10.1179/174313408X353837

[8] Garg, S. and Nath, A. (2008) Female feticide in India: Issues and concerns. Journal of Postgradraduate Medicine, 54, 276-279. doi:10.4103/0022-3859.43511

[9] Harris, G., Connor, L., Bisits, A. and Higginbotham, N. (2008) "Seeing the Baby": Pleasures and dilemmas of ultrasound technologies for primiparous Australian women. Medical Anthropology Quarterly, 18, 23-47. doi:10.1525/maq.2004.18.1.23

[10] Georgsson Ohman, S. and Waldenström, U. (2008) Second-trimester routine ultrasound screening: Expectations and experiences in a nationwide Swedish sample. Ultrasound in Obstetrics and Gynecology, 32, 15-22. doi:10.1002/uog.5273

[11] Enakpene, C.A., Moharson-Bello, I.O., Marinho, A.O., Adedokun, B.O., Kalejaiye, A.O., Sogo, K., et al. (2009) Clients' reasons for prenatal ultrasonography in Ibadan, South West of Nigeria. BMC Women's Health, 9, 12.

[12] World Health Organization (2006) Quality of care: A process for making strategic choices in health systems. http://www.who.int/management/quality/assurance/Qualit yCare_Be.Def.pdf 